\title{
Un camino de posibilidades. Experiencias artísticas en una unidad de oncología pediátrica
}

\author{
Camino BENGOECHEA MENÉNDEZ ${ }^{1}$ \\ Hospital Madrid Montepríncipe \\ caminobm@me.com \\ Carina MOREIRA SÁNCHEZ ${ }^{2}$ \\ Hospital Madrid Montepríncipe \\ carina@espaciorojo.com
}

Recibido: $13 / 11 / 12$

Aceptado: 13/10/13

\section{RESUMEN}

En este artículo presentamos una serie de proyectos de arte desarrollados en la unidad de oncología pediátrica del Hospital Madrid Monteprincipe. En él, sus profesionales trabajan de forma coordinada adaptando su trabajo al niño, y situándolo en el centro de su quehacer diario, destacando el proceso creativo como parte importante en la atención integral del paciente. Presentación de casos reales, metodologías y procedimientos empleados.

Palabras clave: creatividad, oncología, niños, arte, educación, calidad de vida, medicina.

\section{Referencia normalizada}

BengoeChEA MenÉNDEZ, C., Moreira SÁnCheZ, C. (2013). "Un camino de posibilidades. Experiencias artísticas en una unidad de oncología pediátrica". En Arteterapia: Papeles de arteterapia y educación artística para la inclusión social Vol.: 8. Páginas 169-190.

\section{SUMARIO}

Introducción. El cáncer infantil y modalidades de atención en España. Objetivos y metodología de trabajo en la unidad. Un camino de posibilidades. Calidad de vida en Oncología Pediátrica. El proceso creador. Nuestra Experiencia. Arte en sesiones grupales. Sesiones individuales. Conclusiones. Bibliografía.

\footnotetext{
${ }^{1}$ Músico, Musicoterapeuta, Psicopedagoga y terapeuta GIM. Musicoterapeuta en la Unidad de Oncología Pediátrica del Hospital Madrid Montepríncipe. Profesora del Postgrado de Musicoterapia en el Instituto Música, Arte y Proceso de Vitoria y Profesora de la formación en Imagen Guiada y Música (GIM) del instituto MAP.

${ }^{2}$ Artista, educadora. Licenciada en Bellas Artes. Cursos de doctorado U.C.M. Formación pedagógica Waldorf. Ha dirigido la programación en diversos talleres de arte en Madrid. En "Espacio Rojo" coordina proyectos de arte y educación para museos, y otras entidades.
} 


\title{
A path of possibilities. Artistic experiences in a paediatric oncology ward
}

\begin{abstract}
In this paper we present a series of art projects developed in the paediatric oncology unit of Madrid Montepríncipe Hospital. In it, their professionals work in a coordinated manner by adapting the protocol for the child in order to individualize treatment, highlighting the creative process as an important part in the comprehensive care of the patient. Presentation of case studies, methodologies and procedures used.
\end{abstract}

Keywords: Creativity, oncology, children, art, education, quality of life, medical care.

\section{CONTENTS}

Introduction. Childhood cancer and forms of care in Spain. Objectives and methodology of work in the unit. A path of possibilities. Quality of life in paediatric oncology. The creative process. Our Experience. Art in group sessions. Individual sessions. Conclusions. Bibliography.

\section{INTRODUCCIÓN}

El presente texto expone algunas reflexiones, ejemplos de casos y conclusiones acerca de un proyecto de artes plásticas, que se ha llevado a cabo conjuntamente con el departamento de Musicoterapia, dentro del equipo de la unidad de Oncología Pediátrica del Hospital Universitario Madrid Montepríncipe gracias a la Fundación Hospital Madrid. Esta experiencia ha sido posible dado que existe en esta unidad una filosofía de trabajo creada por la doctora López-Ibor centrada principalmente en el niño, donde el objetivo principal será no sólo curar el cáncer sino conseguir que llegue a ser un adulto sano desde el punto de vista físico, psíquico, socia y espiritual.

Este proyecto amplia el proyecto de terapias creativas e integración de las artes que ya se desarrolla en la Unidad desde el año 2005 ofreciendo un espacio de comunicación, confianza y expresión para favorecer espacios abiertos que integren el arte y la cultura a los niños, niñas y sus familias. En este artículo se recogen algunas de las experiencias llevadas a cabo durante la puesta en práctica de este proyecto.

Durante esta experiencia, hemos podido comprobar los cambios favorables que se producían en los niños al inicio del tratamiento y cómo podían crecer de forma integral, observando la importancia que tiene el desarrollo de la creatividad en los niños y niñas enfermos, actividades que les permitían sentirse activos, motivados, participes y actores protagonistas de sus propias vivencias e ilusiones, teniendo otra actitud frente a los tratamientos y la enfermedad.

Cada día vivían con ilusión poder terminar o continuar un trabajo en proceso, esperando y persiguiendo nuevas metas, compartiendo nuevas vías de comunicación consigo mismo y con los demás. En definitiva, teniendo una actitud diferente y otra manera de "estar" en el mundo. 


\section{EL CÁNCER INFANTIL}

En España en el año 2011, 993 niños de edades comprendidas entre 0 y 18 años fueron diagnosticados de cáncer, tratándose de la primera causa de muerte por enfermedad tras el primer año de vida en los países desarrollados. Se trata de una enfermedad grave, cada día más curable, que requiere de un tratamiento complejo, muchas veces largo, en la vida del niño, que afecta de forma determinante a la estructura personal y social de una familia. Durante las últimas décadas, los avances en las técnicas diagnósticas y en los tratamientos del cáncer infantil han mejorado de forma espectacular influyendo en la supervivencia de estos niños, con tratamientos como la quimioterapia combinada, tratamientos de inmunoterapia, transplantes de médula ósea, o determinadas técnicas de neurocirugía, cirugía traumatológica y radioterapia. Además cada vez hay una mayor tendencia a la medicina centrada en la persona que cree en un trabajo holístico que se apoya en equipos de apoyo e intervención psicosocial.

Desde los años ochenta la mortalidad ha disminuido en un 57\%, según indica el informe del Registro Nacional de Tumores Infantiles, aunque todavía en España existen importantes diferencias sociales y geográficas en aspectos como la incidencia, mortalidad, procedimientos y asistencia oncológica, siendo sólo siete las Comunidades Autónomas que han elaborado Planes oncológicos o Estrategias frente al cáncer. Aún así, España es uno de los países europeos en los que la atención sanitaria al niño diagnosticado de cáncer es buena en su conjunto. La puesta en marcha de protocolos nacionales coordinados por las Sociedades Españolas de Hematología y Oncología Pediátricas (SEHOP) y Hematología Pediátrica (SEHP), con la colaboración de las mismas en protocolos internacionales, ha determinado que la supervivencia de un niño diagnosticado de cáncer en España se aproxime al 76,1\%, cifra similar a la de los países de nuestro entorno. En la Unidad de Oncología Pediátrica del Hospital Universitario Madrid Montepríncipe la supervivencia es del $81 \%$. Por tanto hoy en día el objetivo no es sólo curar la enfermedad sino lograr que el niño o niña curado de un cáncer llegue a ser un adulto sano desde un punto de vista integral.

Es por ello que desde la Sociedad Internacional de Oncología Pediátrica (SIOP) se recomienda el tratamiento en unidades especiales que dispongan de los medios humanos y materiales para una correcta asistencia, así como también una atención psicosocial al niño y su familia, coordinada con la atención médica, para ayudar a una mejor tolerancia del tratamiento y mitigar sus secuelas. Por ello las ayudas a la escolarización, necesidades sociales, apoyo psicológico, etc. deben ser tenidas en cuenta en el marco de su atención integrada. Además, el seguimiento sanitario y social de los supervivientes es necesario, como lo es también el seguimiento y apoyo a las familias que han perdido un hijo tras padecer un cáncer. 


\section{OBJETIVOS Y METODOLOGÍA DE TRABAJO EN LA UNIDAD DE ONCOLOGÍA PEDIÁTRICA DEL HOSPITAL UNIVERSITARIO MADRID MONTEPRÍNCIPE}

La Unidad de Hematología y Oncología Pediátrica del Hospital Universitario Madrid Montepríncipe dirigida por la Dra. López-Ibor está integrada en el Departamento de Pediatría, aunque funciona de forma independiente. Los principales objetivos de esta Unidad son (López-Ibor, B. 2006):

- Conseguir el mayor índice de curación de los enfermos.

- Minimizar los efectos secundarios y las complicaciones del tratamiento.

- Conseguir que todo un equipo de profesionales trabaje de forma coordinada para que el niño reciba la atención diagnóstica y terapéutica que necesita en cada momento.

- Utilizar los últimos avances científicos y tecnológicos y trasladarlos a la práctica clínica.

- Integrar la enfermedad en la vida normal del niño y su familia.

- Atender al niño de forma integral cuidando los aspectos médicos, psicológicos, sociales y espirituales durante su enfermedad.

En esta Unidad la atención se realiza desde el momento del diagnóstico, y es el oncólogo el encargado de planificar el tratamiento e integrar en él a los especialistas que puedan requerirse. Según la Dra. López-Ibor, existen unos "momentos claves" en la evolución de su enfermedad y todos ellos son de vital importancia para el buen desarrollo del tratamiento:

\section{Diagnóstico}

El primer ingreso del niño en el hospital es un momento de ansiedad y miedo a lo desconocido. El diagnóstico de presunción lo suele adelantar el pediatra general y es el oncólogo el que en general da el diagnóstico definitivo. Existe, por tanto, un período de tiempo de incertidumbre que debe ser lo más corto posible para aliviar la ansiedad de los padres. Es una de las fases más importantes para poder determinar el tratamiento adecuado. Por ello las pruebas diagnósticas iniciales deben realizarse con carácter preferente. La conversación que el médico mantiene con la familia en este momento es de vital importancia. Mack and Grier (2004) describen en su artículo "The day one talk" las bases para una correcta comunicación de las noticias en este día por parte del médico. Es importante incidir en la claridad y honestidad teniendo en cuenta tres aspectos fundamentales:

1.- Hablar claramente del diagnóstico manejando la incertidumbre que a veces acompaña al proceso, poner en orden los objetivos y el tratamiento a seguir y por último hablar de la causalidad quitando culpabilidad a los padres tanto en la causa como en el momento del diagnóstico.

2.- Es importante saber escuchar a los padres. Los padres son ahora parte de un equipo. Y debemos informar tanto a ellos como a sus hijos acerca de la enfermedad y planificar y supervisar el tratamiento. Su función es enseñarnos 
acerca de sus hijos y ellos mismos, porque esto nos ayudará a proporcionar una mejor atención.

3.-Recordamos a las familias que vamos a estar con ellos durante el tiempo que su hijo o que ellos nos necesiten. Los padres van a ser parte del equipo y este aspecto es muy importante a la hora de llevar a cabo nuestro trabajo.

\section{Inicio del tratamiento}

Es una etapa de suma importancia en el niño y en su familia ya que deben adaptarse a esta nueva realidad y les preocupa que eso sea para siempre. La tolerancia al tratamiento es uno de los objetivos principales en la Unidad de Oncología por ello los tratamientos médicos deben ir siempre acompañados de todo el apoyo del resto de profesionales del equipo que favorezcan una buena tolerancia a los distintos tratamientos.

Dependiendo del tipo de cáncer que tenga el niño se decidirá por un tipo de tratamiento u otro, necesitando en ocasiones la combinación de distintas modalidades de tratamiento.

\section{Etapa de mantenimiento}

En esta fase, los niños y niñas continúan con su tratamiento, que puede ser más o menos complejo según su diagnóstico. Como hemos expuesto, la enfermedad provoca grandes cambios en la vida del niño. Lo más importante en esta fase es que recupere una vida lo más normal posible, regresando al colegio y a sus actividades normales.

\section{Fin de tratamiento}

Esta etapa es de mucha importancia ya que significa que aquello que un día comenzó ha terminado con éxito. Suele celebrarse una fiesta de fin de tratamiento en la que otros niños y niñas, familias que están viviendo en ese momento el comienzo de la enfermedad, ponen ahí su apuesta y esperanza.

\section{Supervivencia a largo plazo}

El niño diagnosticado de cáncer requiere un seguimiento hasta la edad adulta, no sólo para los posibles efectos secundarios a largo plazo (esterilidad, segundos tumores, etc...) sino también para encauzar los problemas de dependencia de los adultos, ayudarles a orientar su futuro desde el punto de vista sanitario y laboral y resolver los problemas de sexualidad y fertilidad que puedan plantearse. La infancia es un periodo vital en la vida del ser humano y, cuando esta etapa se ve alterada por una enfermedad de estas características, el niño ve afectado todo el ambiente que le rodea y le proporcionaba seguridad; es por ello que los vínculos de afectividad, comunicación y juego deben estar cubiertos también en esta etapa de su vida.

Para que el niño llegue a ser un adulto sano debemos considerarle de forma integral, cuidando los aspectos médicos, psicológicos, sociales y espirituales durante su enfermedad. 


\section{Recaída}

Por último, durante el seguimiento que se realiza al niño una vez finalizado el tratamiento, pueden detectarse recaídas de la enfermedad, que requieran nuevos tratamientos dirigidos a su curación o a su estabilización. Cuando la enfermedad se hace resistente al tratamiento y el niño no se puede curar, queda mucho por cuidar continuando a cargo el mismo equipo de profesionales.

López-Ibor (2006) habla de que en esta fase la actitud de los padres atraviesa una serie de etapas en relación con la pérdida de esperanza de que el niño se cure, se plantean si vale la pena comenzar de nuevo, además de los mismos sentimientos que atraviesan en la fase del diagnóstico. En esta fase en muchos casos se plantea la decisión de aplicación de cuidados paliativos donde la medicina pone un mayor énfasis en los cuidados del enfermo más que en la curación del enfermo. En esta fase es fundamental la intervención conjunta del niño y de su familia teniendo en cuenta los aspectos psicológicos y espirituales que se plantean tanto para el niño como para su familia. Como equipo debemos entender que el paso a los cuidados paliativos no supone un salto o derivación del niño a otro tipo de trabajo completamente diferente. El paso al cuidado paliativo supone una reformulación de nuestros objetivos trabajando aún más si cabe todos los objetivos planteados anteriormente pero sabiendo escuchar con mayor atención las necesidades espirituales, afectivas y emocionales de estos niños. Supone entender que nuestro tiempo de trabajo se acaba pero no el del niño que desea más que nunca potenciar todas sus capacidades y que los demás le ayuden a expresarlas y dar forma. Nos damos cuenta e esta etapa que si hemos hecho bien nuestro trabajo el niño contará con los recursos necesarios para despedirse y ser acompañado en este momento de aquello que sólo desea, su familia.

\section{Muerte}

Aún sabiendo en muchas ocasiones que la enfermedad es incurable todo el equipo apuesta desde el principio por la curación del niño y esto que parece obvio no es sencillo de entender y comprender. Pero ocurre que aún empleando el máximo nivel de ciencia, técnica, sabiduría y conocimiento a veces no es posible curarle. El equipo se ha ido poco a poco preparando para ello porque como bien dice la Dra. López-Ibor la muerte no se improvisa. Ello permite preparar a los padres para iniciar el duelo progresivamente. El niño desde edades tempranas, a los 5-6 años sabe cuando las cosas no van bien. Sabemos por diferentes estudios que los niños saben y conocen perfectamente su enfermedad y también saben en esta etapa que las cosas no están funcionando. Por ello debemos preparar al niño desde los múltiples lenguajes a mantener la comunicación y poder expresar todo aquello que les asusta, manejar su incertidumbre y dar oportunidad de expresar sus deseos y ayudarles a materializarlos. Es importante mantener con él una comunicación abierta. El niño tiene miedo al dolor y a la soledad y estos dos temores sí que podemos solucionarlos.

Algunos estudios contemplan que determinados efectos en los niños hospitalizados pueden tener lugar en estas áreas (Benavides, Montoya y González, 2000): 
- Cambios en la vida cotidiana: ruptura de actividades habituales, nuevo entorno y nuevas normas, pérdida de independencia.

- Malestar físico: dolor y malestar, cansancio y agotamiento, limitación de la movilidad.

- Reacciones emocionales: temor y ansiedad, problemas en la imagen corporal...

- Manifestaciones conductuales: conductas de apego excesivo, reacciones de ira y agresividad...

- Proceso educativo y relaciones sociales: dificultades de aprendizaje, fobia escolar, pérdida de contactos sociales.

- Ajuste post-hospitalario: miedos sobre el hospital, pesadilla...

Durante el trabajo con niños de la Unidad, hemos podido comprobar que algunos de estos efectos se producían en el niño al inicio del tratamiento, e iban disminuyendo considerablemente al conocer el entorno, relacionarse con profesionales que les ponían en el centro de su trabajo, acudir al cole y realizar actividades artísticas y lúdicas en relaciones de confianza con personas que se vinculaban de manera individual y emocional con ellos. Por otra parte, no hemos observado casos en donde los niños tuvieran procesos traumáticos relacionados con el hospital, sino todo lo contrario; muchos niños encontraban en esta unidad un segundo hogar en el que se le proponían actividades que les proporcionaban un disfrute y apoyo emocional.

¿Cómo es posible, entonces, que en situaciones de pérdida de control, autonomía e independencia, deterioro de la imagen física, situaciones de aislamiento, etc. puedan producirse efectos transformadores de esa realidad?

\section{UN CAMINO DE POSIBLES}

Un concepto que nos puede ayudar a comprender estos procesos transformadores es el de la resiliencia, que se ha definido como la capacidad de una persona o grupo para seguir proyectándose en el futuro a pesar de acontecimientos desestabilizadores, de condiciones de vida difíciles y de traumas a veces graves (Manciaux, Vanistendael, Lecomte y Cyrulnik. 2001). Aunque vivir un acontecimiento traumático es sin duda doloroso, supone también una oportunidad para tomar conciencia y reestructurar la forma de entender el mundo y nuestros valores. La resiliencia, entendida como la capacidad para mantener un funcionamiento adaptativo de las funciones físicas y psicológicas en situaciones críticas, nunca es una característica absoluta ni se adquiere de una vez para siempre. Es la resultante de un proceso dinámico y evolutivo que varía según las circunstancias, la naturaleza del trauma, el contexto y la etapa de la vida, que puede expresarse de muy diferentes maneras en diferentes culturas. Por tanto, es fruto de la interacción entre el individuo y su entorno. Es por ello que rescatamos en nuestra experiencia la capacidad de afrontamiento individual y de emociones positivas del ser humano, 
favoreciendo los vínculos afectivos, la seguridad en uno mismo y el entorno utilizando la exploración creativa y el pensamiento optimista para que aquello que podría ser una experiencia traumática se convierta en una experiencia de refuerzo y afrontamiento.

De esta manera, es necesario favorecer estos procesos mediante proyectos que propicien una participación activa del niño en esta etapa, ya que necesita continuar, en la medida de lo posible, con aquello que formaba parte de su día a día antes de la enfermedad. En este sentido, el proceso creativo puede ofrecer un vinculo con su experiencia previa a la vida en el hospital, proporcionándole herramientas para una nueva comunicación, ofreciéndole la posibilidad de manifestar sus ideas y emociones a través de experiencias motivadoras, ilusionantes y placenteras. La presencia de la música y su relación con otras artes proporcionan un contexto de normalidad en un ambiente médico.

Entendemos el arte, o su definición, como un medio para expresar la manera de ver el mundo de una determinada sociedad y cultura y un modo individual de expresión del ser humano, relacionado con ese tiempo y lugar.

De esta manera el arte no deja de ser una manera de "ver" el mundo, en el que el ser humano se expresa como ser social, pero también como ser individual, uniendo su dimensión cognitiva y emocional. Así, a partir de una realidad que es el mundo que conocemos y en el cual vivimos, se producen otros mundos posibles, creados a través de la ilusión y la expresión individual.

El arte nos permite representar y percibir la realidad interna y externa del ser humano. En esta definición encontramos que la actividad artística, desde un campo interdisciplinar, puede utilizarse en diferentes áreas contribuyendo a mejorar la integridad emocional y por tanto física de las personas. Hoy en día el arte, la música, la danza, el teatro es utilizado en diferentes áreas, tales como sociales, educativas y también en el ámbito de la salud.

\section{CALIDAD DE VIDA EN ONCOLOGÍA PEDIÁTRICA}

El auge que experimenta la medicina en la década de los años 60 en el campo científico, así como en la universalización de los sistemas sanitarios en Europa, exigen también una mayor humanización de la medicina y del ámbito hospitalario.

La Organización Mundial de la Salud (OMS) en su Constitución, define salud como el estado de completo bienestar físico, mental, espiritual, emocional y social, y no solamente la ausencia de afecciones o enfermedades. En este sentido, las terapias creativas llevan implícitamente una forma diferente de concebir la salud y la enfermedad, pues parten de una concepción holística del ser humano, más positiva e integral, viéndolo en todas sus dimensiones.

El cáncer compromete seriamente la calidad de vida de las personas de muchas y diferentes maneras; como ya mencionamos anteriormente, el tratamiento afecta aspectos físicos, emocionales, la pérdida de hábitos sociales etc. Es por ello que debemos acercarnos a la realidad diaria que experimenta el niño, dándo- 
le la posibilidad de desarrollar todas sus potencialidades y tratando que la enfermedad no sea un paréntesis en la vida del niño.

Varios estudios se han llevado a cabo de forma cuantitativa para medir la calidad de vida; en este sentido, Eiser. C. (2004) va a servirnos de referencia, ya que enfatiza la importancia de medir la calidad de vida de una manera multidimensional, teniendo en cuenta los momentos en que se encuentra el niño en su tratamiento, el impacto que la enfermedad supone en el niño o en sus padres y hermanos, así como las consecuencias que ésta tiene en los supervivientes de la enfermedad.

Los procesos de expresión creativa son conocidos por aumentar la calidad de vida en pacientes adultos y pediátricos. En este sentido, el arte es utilizado como una modalidad de atención psicológica desde los años 50 en los hospitales de EEUU y Reino Unido, donde se encuentra integrado en el sistema general de salud como un servicio más para los pacientes.

El interés que se manifiesta a través de estudios, publicaciones e instituciones médicas hacia otras formas de tratamientos complementarios, tales como el arte y la música tiene que ver con esta concepción integral del ser humano, así como también con la convicción de que el paciente tiene una parte activa en el tratamiento y en la prevención de la enfermedad.

Nuestro proyecto, en este sentido, es trabajar de una forma interdisciplinar, integrando los procesos creativos desde la intervención con musicoterapia, la creación de proyectos de artes visuales, visitas de artistas, excursiones, conciertos, adaptando el hospital al niño, no el niño al hospital.

\section{EL PROCESO CREADOR}

El arte para los niños no significa lo mismo que para los adultos; mientras que para estos el arte suele estar ligado a ciertas habilidades técnicas y al gusto estético, para los niños la expresión artística suele ser algo natural y lúdico, pudiendo expresar con mayor libertad ideas, experiencias y sentimientos que en muchas ocasiones resultan difíciles de expresar verbalmente. Los trazos, las formas y los colores permiten ampliar su registro expresivo, abriendo un espacio de libertad para expresar sus vivencias en un ambiente de confianza y seguridad.

Ligada al proceso evolutivo del niño, la experiencia artística es una herramienta esencial en el ciclo vital del ser humano, ya que con ella se potencian las capacidades psicomotoras, perceptivas y cognitivas, a través de procesos intelectuales de observación y simbolización.

Las expresiones plásticas en la infancia expresan el mundo interior, sus vivencias, su desarrollo intelectual, emotivo y creativo; por tanto, cuanto mayor sea la motivación y la intensidad vivida, mayor será su creatividad y libertad individual.

En este sentido, en los proyectos llevados a cabo en la unidad hemos intentado fomentar estas experiencias personales, a través de imágenes y juegos, adaptán- 
donos a cada nivel de desarrollo, personalidad y sensibilidad para crear obras que les proporcionen satisfacción y confianza en si mismos.

Nuestras sesiones parten de la idea de creatividad como proceso humano y no como un aspecto que atañe sólo al mundo del arte. Desde esta postura, aparentemente tan general, podemos acercar a las diferentes personas que componen la unidad -las familias, los niños, los diferentes usuarios y profesionales-, humanizando la convivencia entre unos y otros, ayudando en el desarrollo y fortalecimiento del niño, en un proceso de adaptación activa de la realidad. Entendemos que si el sujeto se transforma, modifica al medio y, por tanto, se modifica a sí mismo. Bajo este planteamiento, el ser humano puede sentirse parte activa, enfrentar el cambio, el desarrollo y destino de su propia vida.

Para dinamizar estos procesos se realizan en la Unidad proyectos a lo largo del año, que engloban a todo el equipo en tareas comunes, tales como la organización de un mercadillo solidario de navidad donde todas las familias participan en trabajos manuales, artesanales, creativos, conciertos con artistas invitados, semanas culturales con exposiciones de trabajos y libros...Estos procesos fomentan la implicación grupal en trabajos con un fin y una tarea común:

“....en el grupo operativo el esclarecimiento, la comunicación, el aprendizaje y la resolución de tareas coinciden con la curación, creándose así un nuevo esquema referencial. De esta manera el concepto y valor de los grupos lo entenderemos como parte de un aprendizaje que se dirige a la ruptura de estereotipos, a la participación activa del sujeto en el proceso de conocimiento, a la transformación de ambos y a la creatividad." (Pichon-Rivière.1975, p.120)

Para comprender y valorar la metodología de trabajo en una unidad de estas características es importante destacar varios aspectos en el desarrollo de las sesiones, tales como el amplio rango de edad de los niños en tratamiento, que es de 0 a 18 años. Por ello debemos considerar especialmente un trabajo de planificación que permita espacios abiertos al trabajo con diferentes edades y donde todos los niños puedan colaborar, sintiéndose parte de un trabajo común, aportando ideas y sugerencias.

Así, tampoco podemos delimitar nuestro trabajo a una sola manera de realizar las sesiones de arte, ya que nos encontraremos con niños en diferentes fases del tratamiento: éstas pueden consistir en pasar temporadas cortas en el hospital, en tratamientos ambulatorios, o ingresos de meses, días o tratamientos de cirugía que requieran estancias largas en el hospital. Los niños pueden requerir también trasplantes de médula ósea o pasar por etapas de neutropenia en las que necesitan estar aislados en las habitaciones, por lo que es conveniente plantear un trabajo adecuado a estas circunstancias específicas.

Las sesiones de arte se desarrollaron en sesiones de dos días a la semana, realizando trabajos grupales e individuales, planteándonos diferentes objetivos y diversas aproximaciones metodológicas, de acuerdo a las características y necesidades de los niños y niñas hospitalizados según el curso y estado de su enfermedad. 


\section{NUESTRA EXPERIENCIA}

Definiremos tres objetivos generales en nuestro trabajo:

1. Aportar a los niños y sus familias diferentes espacios de participación y encuentro a través de procesos de creación artística. La interacción de las artes también permitirá múltiples formas de expresión y comunicación

2. Ofrecer experiencias de trabajo conjunto. Las tareas comunes permiten relacionar a unos miembros del grupo con otros permitiendo una vinculación y un desarrollo de cada miembro del grupo actuando conforme a sus necesidades y a su satisfacción

3. Potenciar en los niños la práctica del arte y la música como un hábito cultural al alcance de todos. De esta manera contribuimos a su formación como seres humanos que le permitirá sentirse parte de un contexto afectivo, social y cultural.

\section{ARTE EN SESIONES GRUPALES}

Las propuestas artísticas en éste ámbito se desarrollan a partir de reunir en una zona común, en este caso la sala de "hospital de día", a niños en diferentes fases del tratamiento, fomentando así la integración y socialización de diferentes edades y circunstancias, creando un entorno de comunicación, libertad y esparcimiento.

Como señalamos anteriormente nos interesa especialmente destacar el trabajo grupal. Esta vivencia es de vital importancia y debe estar presente también en esta etapa de su vida para ser un adulto sano. Los niños que interactúan en un grupo mediante una experiencia creativa aprenden a verse a sí mismos con los ojos de los demás, a poner en juego sus capacidades expresivas y rebasar sus propios "límites".

En muchas de las sesiones con los niños, el inicio de la actividad se proponía o bien nos uníamos al juego que el niño ya había iniciado. De esta manera, en este primer vinculo de confianza y libertad podíamos proponer otras experiencias de actividades creativas, que surgían de forma natural y no como imposición del adulto. Es importante que el niño sea el protagonista y decida compartiendo una sucesión de ideas, pensamientos, impulsos y sensaciones que, aún sin relación aparente, le permitan ser participes del acto creador. Un rasgo importante del juego es que en él, y quizás solo en él, el niño o el adulto están en libertad de ser creativos. (Winnicott,1997, p.79-80)

En estas sesiones potenciamos el juego con diversos materiales, tales como disfraces o música, para componer otros espacios abiertos a la imaginación creadora. No intentamos crear situaciones de grupo impuestas, sino crear una atmósfera de trabajo que resulte motivadora para cada uno de ellos. En muchas ocasiones se comenzaba de forma individual $\mathrm{y}$, a partir de la motivación creada en un niño y de propuestas sugerentes, podíamos incorporar a otros en el grupo o viceversa. 
La metodología se basa en la experiencia de "taller", donde pueda surgir, a partir de motivaciones o temas propuestos, un encuentro con los diferentes materiales, para así investigar y modificar diferentes elementos buscando su propia respuesta creativa.

Esta metodología permite crear un espacio de experimentación fomentando procesos flexibles, abiertos a la imaginación. De esta manera, el niño/a descubre y explora junto con el profesional nuevas formas y procedimientos, eligiendo entre materiales diversos para cada nuevo proyecto, proponiendo sus propias metas y significados. Esta experiencia ayuda al niño a sentirse "activo" ganando una sensación de participación y dominio, proporcionándole seguridad en si mismo, otorgando a sus obras su propio significado.

A continuación expondremos el caso de una niña en la que el grupo y el proceso creador han funcionado en este sentido, como vehículo para su recuperación:

Para preservar la identidad de los niños se han cambiado los nombres.

En una de estas sesiones se propuso trabajar con la silueta de los niños, colocando los materiales de acuerdo a las circunstancias de cada uno. Elegimos trabajar ocupando diferentes lugares de la sala para que dentro de un espacio común se pudieran poner en práctica también procesos de trabajo individual. Comenzamos a jugar con una niña que propone disfrazarse. Carolina había colaborado en una sesión grupal anterior, donde había ayudado a otra niña que se encontraba mal y no podía terminar su trabajo, ella quiere hacer ahora su propia pintura. El tema elegido: su propio cuerpo en forma de silueta, que para esta sesión se venía trabajando previamente de forma individual y grupal con otros niños de la unidad. En el trascurso de la sesión vamos incorporando a otros niños de diferentes edades, que también como Carolina quieren disfrazarse y participar en la actividad. Se incorpora al grupo Ana de 5 años, quien había sido operada por segunda vez en su pierna. Este hecho requiere tenerla un tiempo inmovilizada y le acompaña su madre. Nos dice que, por recomendaciones médicas, debía procurar moverla poco a poco, siendo esto lo mejor para su recuperación. Le habían quitado el vendaje y ya podía apoyarla en el suelo pero aún tenía miedo de hacerlo. Se muestra entusiasmada con la actividad y quiere participar, pero pone reticencias a la hora de moverse y tumbarse en un papel para plasmar su figura. Le propongo ayudarla, alzando su cuerpo; ve el resultado y el trabajo de las niñas y finalmente decide hacerlo. Disponemos luego su dibujo en una mesa para que pueda pintarlo y se sienta en un sillón; algunos de nosotros íbamos moviendo a Ana en su silla alrededor de la mesa de trabajo; mientras, podía pintar las distintas partes de su cuerpo e iba eligiendo los materiales, modificando las formas y colores adecuados para su dibujo. Le ofrecía colores, mezclas, posibilidades y materiales; a medida que trabajaba se concentraba en su obra, hablaba con el grupo con gran entusiasmo y otras niñas aportaban sus ideas. Mientras trabajaba observamos cómo adoptaba otras posturas, perdiendo los miedos iniciales o la idea de no poder "moverse" como los demás. En el trascurso de la actividad iba perdiendo la postura rígida de su cuerpo, extendía sus brazos, reclinaba sus piernas y apoyaba su pierna recién intervenida. 
De esta manera la actividad se fue adaptando a sus circunstancias y ella a esta experiencia. Proporcionándole estrategias que le permitieron el suficiente estímulo para desafiar sus propios límites sin ser especialmente conciente de ello. El grupo, la actividad creativa y el profesional le dieron la confianza para poder mover su cuerpo, adaptándose en diferentes espacios: tumbarse en el suelo, pintar en una gran mesa y una pintura de grandes dimensiones que le proporcionaron otra visión del espacio y de sí misma, en la que necesitaba moverse, rodear su figura para poder realizarla.

Por otro lado, en esta misma sesión, una niña de mayor edad, subida en otra mesa o recostada en el suelo, iba continuando una pintura que comenzó en sesiones de trabajo individual. Hay que destacar también que Carolina, con la que habíamos iniciado el trabajo en grupo, se sintió cansada y débil ya que tenía que moverse en el suelo, en la pared y desplazarse de un sitio a otro para acabar su pintura, exigiéndole esto una considerable actividad física en el transcurso de su tratamiento. Fue entonces cuando sugerimos que podía descansar en su habitación, y volver cuando quisiera o continuarlo otro día. Pero el entusiasmo por participar en el grupo y concluir su pintura, hizo que la niña volviera al cabo de un rato, por propia iniciativa, con fuerzas y ánimo para continuar.

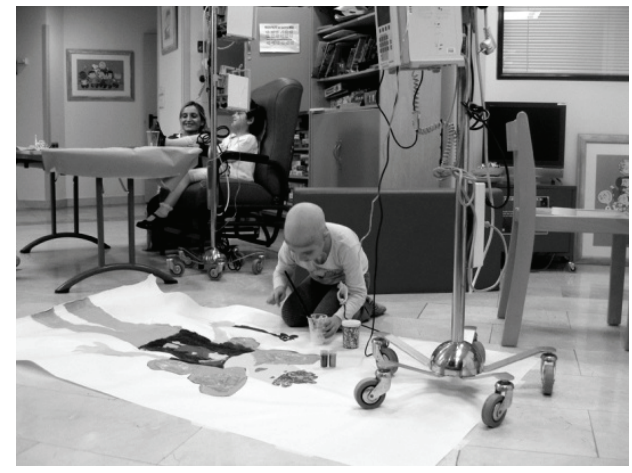

Podemos ver, de esta manera, que en sesiones de trabajo grupal se pueden continuar en un mismo espacio trabajos individuales o viceversa. De esta forma el grupo se enriquece, compartiendo diferentes procesos creativos.

Al finalizar su pintura, la representación de las niñas en forma de "hada" quedó colgada en la puerta de sus habitaciones en el hospital. Así, y desde un lugar simbólico, las niñas "habitando" y construyendo su propio espacio.

tomaron su cuerpo y lo transformaron,

\section{SESIONES INDIVIDUALES}

En muchas ocasiones es necesario llevar a cabo procesos de trabajo individual.

Pueden ser situaciones donde los niños tengan que pasar estancias prolongadas en el hospital, situaciones de aislamiento o recaídas de su enfermedad.

El trabajo en estas sesiones serán proyectos ajustados a necesidades especificas que consideremos pueden servir para unos objetivos a corto o a largo plazo, dependiendo del tiempo del que podamos disponer para trabajar con esa persona. Así también estarán adaptados a su etapa de desarrollo a nivel cognitivo, físico y emocional. 
La elaboración de un proyecto o propuesta conjunta de trabajo individual permiten fijar metas, elaborar objetivos que se transforman a medida que el niño se implique o no en él, elaborando motivaciones para llevarlo a cabo, dado que tiene una continuidad en el tiempo.

Nuestros principales objetivos en el trabajo individual serán:

- Establecer vínculos de confianza y comunicación entre el profesional y el niño

- Favorecer la autoestima y el fortalecimiento anímico a través de la creatividad

- Potenciar las destrezas y aptitudes personales y expresivas

- Crear espacios de trabajo que favorezcan momentos de reflexión, interiorización y conexión con uno mismo

Estos objetivos nos permitirán desarrollar proyectos que crezcan y se desarrollen con un nexo o idea común, en el que el niño aprende nuevas y diferentes formas de expresarse en un trabajo que le permitirá identificarse con su obra y verse reflejado en su proceso creativo.

La experiencia nos ha demostrado que un proyecto puede favorecer vínculos de comunicación mas íntimos entre el niño y el profesional, y en este sentido también de relajación, dada la confianza que se establece entre ambos. Esto le permite al niño hablar de otros temas que le interesan, compartiendo sus experiencias, preocupaciones y sentimientos fuera del ámbito familiar.

Por otro lado, esta experiencia de trabajo favorece la confianza y autoestima en el niño, ya que en estas propuestas él/ella podrán percibir el cambio que se produce poco a poco en su trabajo, a través de ensayo y error, posible e imposible, seguridad e inseguridad y un largo etc., que le proporcionan el necesario impulso, motivación y fuerzas para continuarlo y perseverar en él, formando parte de algo, con el sentimiento de que puede contribuir de forma activa en su desarrollo. Así, mientras el niño se enfrenta a un proceso de transformación de su identidad y realidad como consecuencia del tratamiento de quimioterapia, cirugía, radioterapia, etc. podremos contribuir a modificar su entorno y, como consecuencia, a sí mismo.

En este sentido, hemos podido comprobar que se producían momentos de tensión cuando el material o la forma no respondían a sus expectativas; muchas veces había que comenzar todo de nuevo y destruir lo ya creado. Este proceso de transformación, con ese riesgo de caos que señala Hector Fiorini en El psiquismo creador (Fiorini, H. 2007) dado en un espacio y tiempo adecuados, proporciona nuevas formas y procesos que pueden provocar mayor predisposición a los cambios, flexibilidad, apertura y fortaleza en la personalidad del niño.

De esta manera el proceso creador nos ofrece una alternativa a lo real y nos proporciona un estado de disponibilidad. En palabras del poeta José Ángel Valente "Crear es generar un estado de disponibilidad, en el que la primera cosa creada es el vacío, (...). Pues lo único que el artista crea es el espacio de la creación.” 
En este sentido, durante este trabajo buscaremos estos espacios de creación posibles y vinculantes, para generar un tiempo y espacio adaptado al niño y sus necesidades, donde se registren estos procesos modificadores que propicien en la persona mayor confianza para tomar decisiones, mayor tolerancia hacía sí mismo y hacia los demás.

Refiriéndonos al valor e importancia de estos procesos de trabajo individual, expondremos como ejemplo diferentes proyectos llevados a cabo con una niña.

a) Proyecto de cine-animación

Elena llevaba poco tiempo ingresada en la Unidad pero, dada las características de su enfermedad, sabíamos que debíamos realizar con ella un trabajo continuado en el tiempo. Sus aptitudes artísticas se hacían evidentes y también sus ganas y buena predisposición a las diferentes propuestas. En una de las primeras sesiones le propusimos realizar un trabajo de animación que veníamos realizando como experiencia previa con otros niños de la Unidad.

Se trataba de realizar en un principio "flipbooks" o pequeños libros animados, para más adelante trabajar pintando directamente en celuloide o película de cine. En esta primera sesión dibujamos con ella en un pequeño libro, explicándole la forma en la que debíamos hacerlo para que al introducir un pequeño cambio en cada página, cuando éstas pasasen rápidamente, las imágenes parecieran animarse simulando un movimiento u otro. Esta primera actividad estableció, por un lado, un primer vínculo de confianza, ya que su flipbook iba pasando por su mano y luego le ayudábamos a dibujar otras páginas.

Por otro lado, la transformación como tema simbólico del cambio está presente en los pacientes que atraviesan esta enfermedad y aquí es tratado a través de un ejercicio de animación. Al principio Elena no se decidía a dibujar. Finalmente dibujó a lápiz un niño subiendo una escalera, y ella comentó también la necesidad de pensar en un título para su historia.

En otras sesiones el trabajo de animación se continúa pintando sobre película de cine de $16 \mathrm{~mm}$., previamente limpia de emulsión. El trabajo consiste en pintar en cada fotograma, pero teniendo en cuenta que por cada 24 fotogramas pintados sólo se verán posteriormente en la pantalla 1 segundo de la película. Para este trabajo se manipularon y comentaron zootropos y vimos películas de cine "hecho a mano".

Elena realiza entonces con mucha minuciosidad pequeños dibujos en cada uno de los fotogramas utilizando pocos colores. A pesar de cierta dificultad en su mano, por tener recientemente colocado el catéter por el que recibe su tratamiento, se empeña en contar cuantos dibujos le faltan para llegar a un

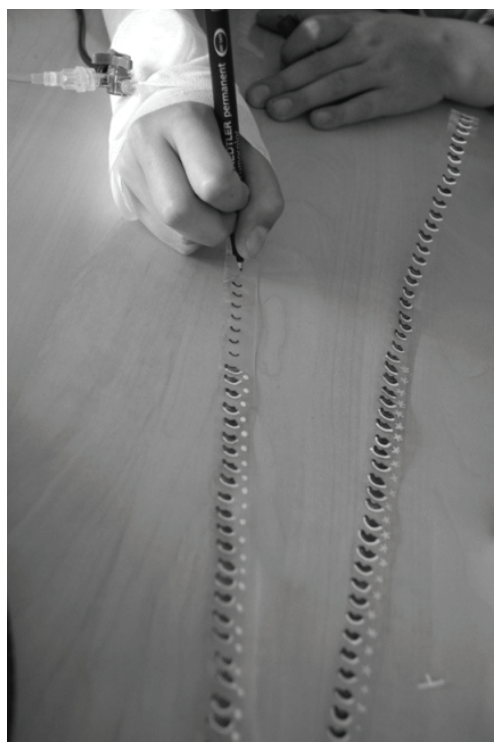


segundo de tiempo! Es todo un descubrimiento para ella saber que así funcionan las imágenes que vemos y se entusiasma con ello, al punto de llevarse también película para seguir trabajando después de la sesión. La aportación principal desde un punto de vista cognitivo y subjetivo fue descubrir a través de la tira de celuloide que el tiempo ocupa un espacio; ello suponía preguntarse cuanto tiempo tenía en sus manos, si uno o medio segundo, a través de un nuevo soporte, el de la película fílmica utilizada como lienzo.

En este sentido, es importante destacar el significado que tiene esto último para los niños que reciben tratamiento oncológico, ya que uno de los objetivos trata de que el paso por el hospital no sea una interrupción en el trascurso de su vida. De esta manera, trabajar la noción del tiempo desde otra dimensión creativa y simbólica ayuda a los niños a valorar cada paso o segundo como parte de un todo que formará parte de su vida.

b) Proyecto de escultura

Elena sufre nuevamente una recaída de su enfermedad. Nos volvemos a ver después de muchos meses en los que ha recibido sólo tratamientos ambulatorios. Al cabo de seis meses recae de nuevo. Siente una gran frustración y desánimo por volver a tener que ingresar en el hospital y esta fase de su tratamiento será larga y más intensa. Requerirá tratamiento con quimioterapia, radioterapia y trasplante de médula autólogo. Esto implica un largo periodo de aislamiento. Entonces decidimos trabajar con ella el cuerpo físico desde todas sus dimensiones. Mientras asiste a sesiones de musicoterapia, realizamos sesiones de trabajo individual, que tuvieron como tema el cuerpo físico, el movimiento y su representación en la figura humana. Elegimos, abordar este tema desde diferentes procedimientos y materiales.

Como comentamos anteriormente, Elena tiene muchas aptitudes artísticas. Es activa, participativa y sociable. Tratándose de una niña en etapa preadolescente, nos pareció importante que sus aptitudes y valores personales se potencien y desarrollen de la mejor manera posible, ya que el tratamiento oncológico interfiere en este proceso, alterando su imagen y su cuerpo.

Debemos recordar también que en esta etapa adolescente surge la autoidentificación, como un proceso de afirmación de su propia identidad; una búsqueda de independencia y de afirmación a través de las relaciones sociales con amigos y compañeros. De esta manera, casi todo el proceso natural e intereses del niño en esta etapa se verán afectados por su enfermedad.

En estas sesiones, para cada nuevo proyecto propuesto se introducen imágenes de artistas para ser comentadas y utilizadas como motivación y disparador de ideas acerca del cuerpo y el movimiento. Surgen así comentarios de los niños que ayudan a establecer también otro tipo de expresiones, comunicando sus sentimientos y valores generando y aportando ideas a través de las imágenes propuestas. En este caso se utilizan las pinturas del artista Marc Chagall "Los tres acróbatas", de 1926. La obra de este artista es seleccionada por el colorido, la vitalidad y el movimiento sugerente, exacerbado, de la figura. 
La relación con estas imágenes no sólo tiene una función motivadora sino también una perspectiva educativa: ampliar el registro de imágenes que le aporten una mayor sensibilidad estética, cultivando su interés y curiosidad por diferentes artistas y épocas. Son obras en las que se pueden identificar y de las que se pueden apropiar, creando nuevas aportaciones desde su propia individualidad y originalidad

La sesión se inicia en un principio como una actividad grupal, ya que ese día era de especial interés trabajar integrando a varios niños en la sala de hospital de día, utilizada en este caso como "taller".

Elena se encuentra recibiendo un nuevo tratamiento de quimioterapia. Le provoca mucho malestar y dolor de cabeza. Realizamos la propuesta de forma general, uniendo materiales diversos como alambre, cinta, y papel para componer con ellos una figura humana, rellenando con papel las diferentes partes del cuerpo y añadiendo la cabeza.

Elena comparte con los demás su malestar y cansancio. Ella empieza a trabajar su figura con alambre mostrando interés, pero no puede continuar y otra niña más pequeña la ayuda a componer las partes de la figura. En esta primera sesión, Elena pudo sentirse acompañada, recibida, en un espacio donde poder comunicar sus sentimientos de forma activa.

En las siguientes sesiones trabajamos en diferentes lugares tales como en su habitación, en salas de estar, despachos etc. De esta manera nos adaptamos a la situación en la que el niño se encuentre, a su grado de disponibilidad, su situación familiar y la relación con los demás niños de la Unidad.

Continuamos el trabajo de la figura de manera individual, eligiendo la postura que adoptaría y el soporte adecuado para su figura. La fue rellenando con papel primero y luego escayola para en próximas ocasiones pintarla. Este proceso creativo, que fue continuado en el tiempo permitió ampliar la confianza y el afecto mutuo. Elena esperaba el día para poder encontrarnos y seguir trabajando en su obra con nuevas ideas, con ganas de conocer, aprender y trabajar con materiales diversos. En este sentido, debemos añadir que la variedad y originalidad de materiales y procedimientos proporcionaban un especial entorno promoviendo un contexto de "normalidad" y "atrevimiento" en el ámbito hospitalario.

A medida que el trabajo crecía, ella proponía nuevas ideas a desarrollar. Fue así como, ya en los siguientes encuentros, Elena quiso componer una pieza más compleja en la que se integraban varias figuras en equilibrio. Para ello fueron necesarias varias sesiones en las que demostraba una gran destreza con los materiales. Observaba y se detenía en los pequeños detalles y, sobre todo, fue creciendo su seguridad y flexibilidad, al afrontar algunas dificultades técnicas con los materiales o las medidas de las figuras que iba creando. Tenía pensamientos positivos sobre el resultado final, o demostraba gran capacidad para adaptarse a los cambios que el propio proceso creativo iba imponiendo.

Por ejemplo, en una de las sesiones tenía que unir las figuras en equilibrio pero no lograba que la escultura se sustentara como lo había imaginado. Fue un momento muy difícil, ya que las soluciones que le proponía no eran las esperadas. 
Por otro lado, el trabajo había resultado muy largo y era el momento de ver concluida la escultura. Frente a su desanimo inicial, pudo abandonar su trabajo, darle tiempo al material para encontrar soluciones en próximas ocasiones.

Elena tenía una gran confianza depositada en si misma, en la actividad y en mi persona. Gracias a procesos de trabajo anteriores, había aprendido que en el arte, como en la vida, no hay sólo una manera de solucionar las cosas, que iba a poder encontrar alternativas y por ello, también era posible la espera. Muchos artistas han expresado en sus obras y escritos esta idea de transformación de la obra, del tiempo, espera y confianza en el proceso mismo de la creación. Nos hemos acercado al trabajo y al pensamiento del artista Andy Goldsworthy, enseñando a los niños y niñas sus videos y fotografías en donde documenta el proceso de trabajo en la naturaleza; obras que quedan al aire libre, sometidas a las inclemencias del tiempo; piezas que parecen imposibles, creadas enteramente de hojas, piedras o hielo, que duran unos días o apenas unos segundos, ya que se derrumban después de mucho esfuerzo. La importancia está en la experiencia creadora, en los derrumbamientos y también en los errores, comenta Goldsworthy (2007)

En este sentido, nuestra idea de la for-

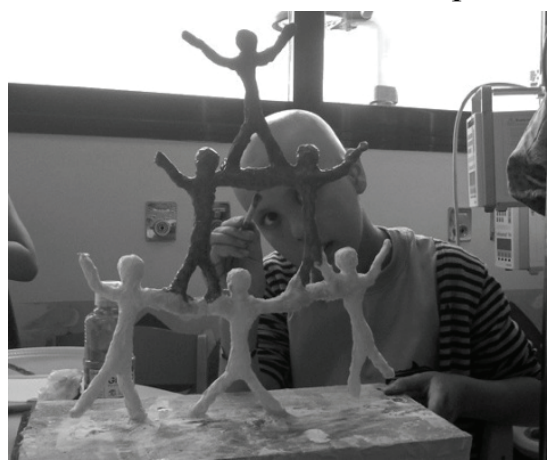
taleza o la debilidad y la manera de afrontar las dificultades puede variar en función también de nuestra percepción de las cosas. De este modo, todo el trabajo y esfuerzo de Elena ha sido muy importante para afrontar su enfermedad y el largo tratamiento de una manera positiva, flexible a los cambios y con un alto concepto de si misma.

Cuando su escultura se secó decidió pintar cada pequeña figura con un color, y elegir en cada una de ellas a un miembro de su familia, ocupando ella el lugar más alto de la pirámide.

c) Proyecto de pintura mural:

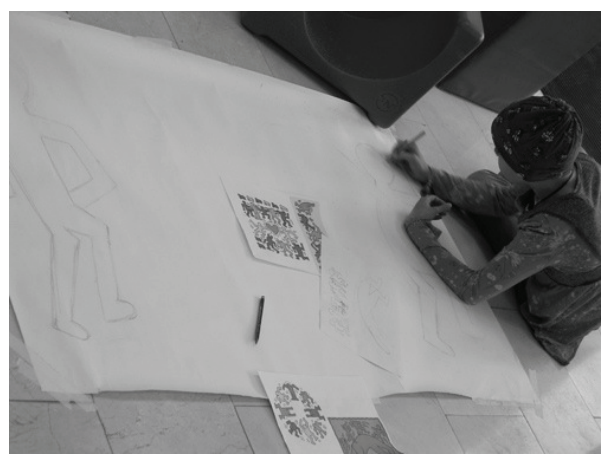

En este proyecto comenzamos con la obra del artista Keith Haring, 19581990. En su trabajo, la utilización de las figuras en movimiento, el uso expresivo del color y su estética personal nos proporcionan en este caso una fuerte motivación para comenzar un nuevo proyecto.

Para su pintura Elena realizó en varias sesiones dibujos pequeños a lápiz con pequeñas figuras entrelazadas, un 
trabajo que se relacionaba con las figuras en estructura piramidal que había realizado con antelación. En este caso dibujó figuras o monigotes danzando en los que se preocupaba por que fueran proporcionados o armónicos, se daban la mano y parecían jugar entre ellos.

Este pequeño dibujo resultó ser un boceto para una pintura mural de gran dimensión. Elena trabajó para ello con el papel en el suelo, adoptando diferentes posturas.

En una ocasión, trabajamos varias horas en un despacho utilizado como "taller" dentro de la Unidad; ese día Elena trabajó casi en absoluto silencio, sólo pintando. En general, mientras trabajábamos ella comentaba sus inquietudes, sentimientos, pensamientos acerca de su familia, amigos, el entorno del hospital, su obra. Pero en este caso sólo necesitaba mantenerse activa, acompañada, en un ambiente de confianza, con una actividad que le proporcionaba calma y disfrute. Las horas fueron pasando y, ya de noche, sus padres vinieron a buscarla preocupados; cuando Elena se fue ya se encontraba cansada, pero feliz de haber encontrado ese espacio significativo que le aportó lo que necesitaba expresar, en un clima de aceptación y confianza.

d) Proyecto de sombras

Continuando con la idea de la representación de la figura humana y el trabajo corporal, trabajamos durante una sesión con esta misma idea, la proyección de su propio cuerpo, manifestando su presencia y silueta a través de una fuente de luz en una pantalla.

Trabajamos con la idea de la dramatización, utilizando pañuelos, gorros y demás elementos para usar como disfraz. Partiendo de música, sonidos y juegos de expresión corporal, surgieron mediante la improvisación historias fantásticas, ridículas, y dramáticas.

Según G. Jung, la sombra es el conjunto de las frustraciones, las experiencias dolorosas, temores, inseguridades, rencor, agresividad que se alojan en el inconsciente del ser humano. La sombra contiene todo lo negativo de la personalidad que el yo, o la parte consciente, no está siempre en condiciones de asumir.

Gracias a la intermediación de una pantalla Elena dejaba de ser ella para proyectarse en la mirada del otro. Este trabajo proporcionó un ambiente divertido en la sala de hospital; de gran energía vital. Una sala completamente a oscuras, la música en un volumen alto y la imagen de Elena que se movía con fuerte intensidad. Esta experiencia le ofrecía la posibilidad de comunicar sin necesidad de hablar, dando lugar a la espontaneidad, fortaleciendo su identidad, reforzando facetas de su propia personalidad, jugando con las formas que le permitieron arriesgarse, perdiendo control sobre su cuerpo para que su sombra hablara, dando luz a su propia sombra. 


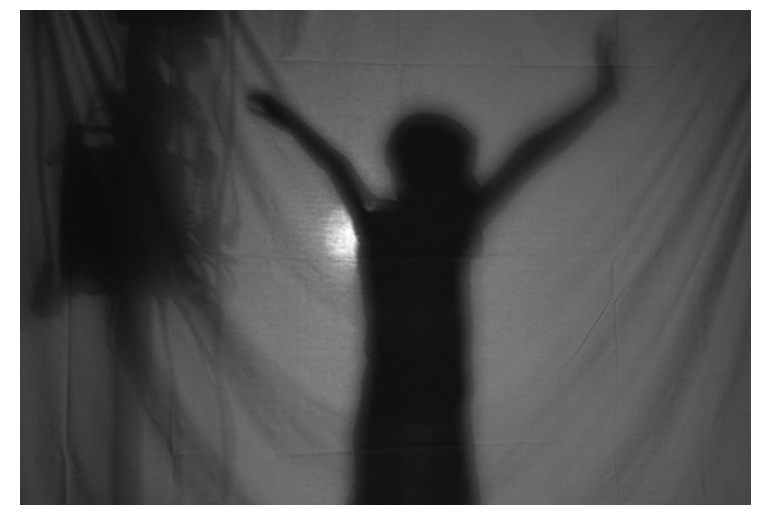

\section{CONCLUSIONES}

Durante todo el proyecto se llevó a cabo un registro escrito, documentando este proceso con comentarios, tanto de los niños y niñas participantes como de las familias, fotografías y videos. Todo este registro es parte de un seguimiento global del paciente que realiza el Departamento Psicosocial de la Unidad. Dadas las características de intervención descritas en este proyecto, no se pretende llegar a conclusiones de índole psicológicas sino relatar nuestra experiencia rescatando el valor del arte desde un punto de vista educativo, social y como desarrollo personal (físico y emocional).

Durante este proyecto hemos podido rescatar los valores intrínsecos de la expresión creadora. En actividades grupales, los niños y niñas fueron invitados a participar en juegos y a crear, desde esta participación, otro espacio y otras maneras de "estar" consigo mismo y con los demás. El espacio de la creación no sólo supuso participar en él, sino crearlo desde la imaginación, el entusiasmo y el "ser capaz de hacerlo", en una nueva adaptación de su realidad. Para Ana, no fue sólo un cambio en su postura o movilidad física sino también una apertura a nuevas posibilidades, una disposición a tomar riesgos, a perder el miedo. Viendo su silueta de pie, pintada en su habitación, estaba satisfecha con ella misma, alegre y acompañada.

De forma individual hemos podido comprobar que la participación en proyectos aportaba en el niño o niña una implicación más activa y comprometida con su tarea, en muchas ocasiones continuándola en ausencia del profesional. Esta implicación conseguía mantener la motivación en todo el proceso y querer implicarse en nuevos proyectos. En el trabajo de animación, pintando directamente sobre el celuloide, la repetición cobraba un sentido, cada uno de sus dibujos formaba parte de un todo, necesario para efectuar el movimiento. En una situación de transformación y permanente cambio exterior e interior, este ritmo ayuda 
a valorar el concepto de que cada paso es importante y forma parte de un todo que aporta sentido a nuestra existencia.

Desde un aspecto pedagógico, esta actividad implica pensar el origen de las imágenes en movimiento, su relación con la pintura, y la fotografía, conocer nuevos soportes, materiales y sus posibilidades creativas. A partir de este proyecto surgieron muchos más creados con programas de animación por ordenador, añadiendo música, historias, fotografías etc.

En los siguientes proyectos, donde el tema esencial era el cuerpo, pudimos abordar diferentes aspectos de la actividad creadora y comprobar sus múltiples aportaciones.

Todas ellas se reflejan en las obras de Elena: en su escultura llena de color subyace un duro trabajo de paciencia y espera, un espacio de la creación en donde aprendió a tolerar la frustración, a lidiar con diversos materiales manteniéndolos en equilibrio, a confiar.

La pintura mural le ha permitido ampliar su capacidad para planificar, esbozar y componer una idea, utilizando el color como medio expresivo y emocional. También en esos momentos supuso un espacio significativo, un momento para la reflexión e interiorización. A través del juego de sombras, improvisando y dramatizando, Elena pudo dejarse llevar, liberar sus miedos gritando, bailando, improvisando movimientos, compartiendo este momento con otros niños y niñas en diferentes circunstancias, reírse de si misma con y de los demás, superando la vergüenza e incluso caerse con la risa y el juego. Compartir estos momentos de energía desbordada, cerrar la puerta de la sala para que los niños y niñas ocupen su espacio y su tiempo, hace que se sientan los actores protagonistas de su propia historia. Esta experiencia supone un camino de autoafirmación y de fuerza vital de suma importancia no sólo para el transcurso de su enfermedad sino también desde la superación. Sobreviven como personas creativas, que han sabido adaptarse a una nueva realidad, desarrollando todas sus potencialidades, construyendo y fortaleciendo ese "yo" que todos y todas llevamos dentro.

Señalaba Viktor Ullman, músico asesinado en Auschwitz y que trabajó con otros creadores en el guetto de Theresienstadt, que "la capacidad de crear es similar a la capacidad de sobrevivir". Crear, en su sentido más amplio, es apostar por estar en el mundo. (López Fernández Cao, Marian. 2011)

Esta nueva manera de "estar" en el mundo consigo mismo y con los demás confiere sentido a nuestra existencia como ser irrepetible, único, asumiendo la responsabilidad, el valor y la belleza de nuestra propia vida.

\section{REFERENCIAS BIBLIOGRÁFICAS}

BENAVIDES, G. MONTOYA, I. Y GONZÁLEZ, R. (2000) La experiencia de la hospitalización en la infancia. En M. Costa (coord.). El Juego y el juguete en la hospitalización infantil. Valencia: Nau Libres. 
EISER, C. (2004). Children with cancer: The quality of life. Mahwah, New Jersey. Lawrence Erlbaum Associates, Publishers.

FIORINI HECTOR J. (2007) El psiquismo creador. Editorial Vitoria. Agruparte.

GOLDSWORTHY, A. (2007). Madrid. Museo Nacional Centro de Arte Reina Sofía

LÓPEZ FERNÁNDEZ CAO, M. (2011) De la función estética y pedagógica a la función social y terapéutica. En M. Ángeles Carnacea Cruz. Ana E. Lozano Cámbara (coords.) 2011 Arte, intervención y acción social: la creatividad transformada. Madrid. Grupo 5

LÓPEZ-IBOR, B (2006) Memoria oncología. Unidad de Oncología y hematología pediátrica del Hospital de Madrid. www.hospitaldemadrid.com/monte_oncopediatria.aspx

MANCIAUX, M., VANISTENDAEL, S., LECOMTE, J. Y CYRULNIK, B. (2001). La resiliencia: estado de la cuestión. En M. Manciaux Ed. La resiliencia: resistir y rehacerse. Madrid: Gedisa, 2003

MACK, JENNIFER W. AND GRIER, HOLCOMBE E. (2004) "The day one Talk". Journall of clinical Oncology. The arto f Oncology. When the Tumor in not a target. Vol. 22. No. 3 february 12004

PICHON-RIVIÈRE, E. (1975) El Proceso Grupal. Buenos Aires. Nueva Visión.

WINNICOTT .D. (1997) Realidad y Juego. Barcelona. Gedisa 